\title{
EFFECT OF INTRA-UTERINE PLASTIC SPIRALS AND HCG ON THE CORPUS LUTEUM OF THE EWE
}

\author{
F. STORMSHAK, R. P. LEHMANN AND H. W. HAWK \\ Animal Husbandry Research Division, U.S. Department of Agriculture, \\ Beltsville, Maryland, U.S.A. \\ (Received 23rd July 1966)
}

\begin{abstract}
Summary. Plastic spirals were surgically inserted into one uterine horn of thirty-two ewes and into both uterine horns of four salpingectomized ewes on Days 4 and 6 of the oestrous cycle, respectively (1st day of oestrus $=$ Day 1). Sham operations were performed on controls. Ewes were autopsied on Day 8 of a subsequent oestrous cycle.

The presence of a plastic spiral either in the anterior or posterior portion of the uterine horn interfered with development of the corpus luteum (CL) in the adjacent but not of that in the opposite ovary. The administration of 1600 i.u. of HCG/day from Days 3 to 6 of the oestrous cycle counteracted the inhibitory effect of the spiral on at development. Intra-uterine spirals interfered with cL development in salpingectomized ewes, thus eliminating the oviduct as a major pathway through which the inhibitory effect of the spiral on the cL is mediated.

The oestrous cycle during which spirals were inserted was not consistently shortened when the GL were present only in the ovary adjacent to the operated uterine horn.
\end{abstract}

\section{INTRODUCTION}

Intra-uterine devices result in shortened oestrous cycles in the ewe (Moore \& Nalbandov, 1953; Inskeep, Oloufa, Howland, Pope \& Gasida, 1962; Ginther, Pope \& Casida, 1966), cow (Hansel \& Wagner, 1960; Hawk, Conley, Brinsfield $\&$ Righter, 1964) and guinea-pig (Bland \& Donovan, 1965a). These shortened oestrous cycles result through an inhibitory effect of the device on the corpus luteum (Bland \& Donovan, 1965b; Ginther, Pope \& Casida, 1966; Ginther, Woody, Janakiraman \& Casida, 1966).

An experiment was designed to study intra-uterine location and exogenous gonadotrophin as factors capable of modifying the effect of plastic spirals on the $\mathrm{CL}$ of the ewe. The possibility that the oviduct might act as a pathway for a local CL inhibitor was also studied.

\section{MATERIALS AND METHODS}

Experiment I. Effect of location of intra-uterine spirals and of injected HCG on luteal development

Forty mature Merino ewes were used in this experiment. Oestrus was detected through checks twice daily with vasectomized rams. All ewes com- 
pleted at least one pretreatment oestrous cycle of normal length (15 to 20 days) before being assigned randomly to one sham-operated control group (Group 1) and three treatment groups. Ewes in the latter three groups received the following treatments: Group 2, plastic spiral (outer diameter, oD, $=12 \mathrm{~mm}$, length $=$ $25.4 \mathrm{~mm}$ ) inserted into the anterior portion of one uterine horn; Group 3, plastic spiral (OD $=12 \mathrm{~mm}$, length $=25.4 \mathrm{~mm}$ ) inserted into the anterior portion of one uterine horn +1600 i.u. of $\mathrm{HCG} /$ day administered subcutaneously twice daily in equal doses from Days 3 to 6 of the oestrous cycle (1st day of oestrus $=$ Day I); and Group 4, plastic spiral $(\mathrm{OD}=15 \mathrm{~mm}$, length $=25.4 \mathrm{~mm})$ inserted into the posterior portion of one uterine horn. Spirals of larger diameter were used in the posterior location to minimize intra-uterine movement.

The spirals were prepared by winding a polyethylene $\operatorname{rod}(3 \mathrm{~mm} d)$ around a wooden dowel of appropriate diameter and immersing it in boiling water for $5 \mathrm{~min}$. The uterine horn into which the spiral was to be inserted was assigned randomly at the time of laparotomy.

Ewes were anaesthetized with an intravenous injection of sodium pentobarbital on Day 4 of the oestrous cycle (hereafter referred to as the 'operative' oestrous cycle). The uterine horns were exposed through a mid-ventral laparotomy and a small incision was made in the antimesometrial side of one uterine horn in all ewes. The spiral was inserted so as to lie in the anterior portion of the uterine horn about $5 \mathrm{~cm}$ from the tubo-uterine junction in animals of Groups 2 and 3 or in the posterior portion of the uterine horn dorsal to the adjacent ovary in animals of Group 4. In this experiment plastic spirals were not sutured in place. The number of CL and their location (right or left ovary) relative to the operated uterine horn was recorded. All ewes were allowed a recovery period equal to the duration of the remainder of the normal oestrous cycle.

Ewes were re-laparotomized on the 3rd day of the first oestrous cycle following the recovery period (hereafter referred to as the 'treatment' oestrous cycle). The position and number of developing corpora lutea were recorded to allow positive identification of these structures at autopsy. Ewes in Group 3 received the first injection of HCG immediately after laparotomy.

Ginther, Pope \& Casida (1966) weighed the CL of ewes on Day 6 of the oestrous cycle to examine the effects of intra-uterine plastic spirals. An initial experiment was conducted in this laboratory in which ewes were also autopsied on Day 6 . The variation in luteal weights both in control and treated ewes was of such magnitude at this particular stage of CL development as to warrant the autopsy of ewes at a later stage. In the experiments reported here, ewes were autopsied or re-laparotomized and ovariectomized on Day 8 of the 'treatment' oestrous cycle. The corpora lutea were enucleated from the ovarian stromal tissue and weighed to the nearest tenth of a milligram. The location of the spiral in the uterine horn was noted.

Data on 'operative' oestrous cycle length for ewes with one or two CL in one ovary only were analysed statistically by weighted means analysis for disproportionate subclass numbers. Data for ewes in Groups 2 and 3 were pooled for this analysis.

For purposes of statistical analysis of luteal weights, obtained at autopsy on 
Day 8 of the 'treatment' oestrous cycle, ewes were further subdivided into those with: (a) GL in the ovary adjacent, and (b) CL in the ovary opposite to the operated uterine horn. Data were analysed statistically by analysis of variance for disproportionate subclass numbers. The average luteal weight was calculated for those ewes with more than one cL and this figure was used in the statistical analysis.

Experiment II. Effect of intra-uterine spirals on luteal development of salpingectomized ewes

Seven crossbred ewes were available that had been bilaterally salpingectomized before the beginning of the breeding season. Oestrus was detected in these ewes as described above. The average length of the pretreatment oestrous cycle in these ewes was 16.5 days (range 15 to 17 days). These animals were assigned randomly either to a sham-operated control or treatment group. Treatment consisted of the surgical insertion of a plastic spiral ( $O D=12 \mathrm{~mm}$, length $=25.4$ $\mathrm{mm}$ ) into the anterior portion of both uterine horns. The plastic spirals were sutured in place in this study. Spirals were inserted on Day 6 of one oestrous cycle and CL weights were obtained at autopsy on Day 8 of the subsequent oestrous cycle.

Data were analysed statistically by analysis of variance.

\section{RESULTS}

Experiment I. Effect of location of intra-uterine spirals and of injected HCG on luteal development

The average weights of cL formed as a result of spontaneous ovulation following onset of oestrus 8 days before autopsy of ewes are given in Table 1. The

TABLE 1

EFFECT OF LOCATION OF INTRA-UTERINE SPIRAL AND OF INJECTED HCG ON THE AVERAGE WEIGHT OF GORPORA LUTEA IN EWES

\begin{tabular}{|c|c|c|c|c|c|c|}
\hline \multirow{4}{*}{$\begin{array}{l}\text { Intra-uterine } \\
\text { location of spiral }\end{array}$} & \multicolumn{6}{|c|}{ Location of corpora lutea relative to operated uterine horn } \\
\hline & \multicolumn{3}{|c|}{ Adjacent ovary } & \multicolumn{3}{|c|}{ Opposite ovary } \\
\hline & \multirow[t]{2}{*}{ Group } & \multirow{2}{*}{$\begin{array}{l}\text { No. of } \\
\text { ewes* }\end{array}$} & $\begin{array}{l}\text { Average wt } \\
\text { of } C L\end{array}$ & \multirow[t]{2}{*}{ Group } & \multirow{2}{*}{$\begin{array}{l}\text { No. of } \\
\text { of ewes }\end{array}$} & $\begin{array}{l}\text { Average wt } \\
\quad \text { of } C L\end{array}$ \\
\hline & & & $(m g) \quad S . E$. & & & $(m g) \quad S . E$ \\
\hline \multirow{2}{*}{$\begin{array}{l}\text { None } \\
\text { Anterior horn } \\
\text { Anterior horn } \\
\quad+\text { injected HGG } \\
\text { Posterior horn }\end{array}$} & $\begin{array}{l}1 \mathrm{~A} \\
2 \mathrm{~A}\end{array}$ & $\begin{array}{l}6 \\
6\end{array}$ & $\begin{array}{l}457 \cdot 8 \pm 34 \cdot 6 \\
181 \cdot 5 \pm 60 \cdot 8\end{array}$ & $\begin{array}{l}1 \mathbf{B} \\
2 \mathrm{~B}\end{array}$ & $\begin{array}{l}4 \\
8\end{array}$ & $\begin{array}{l}388 \cdot 8 \pm 25 \cdot 6 \\
544 \cdot 7 \pm 41 \cdot 6\end{array}$ \\
\hline & $\begin{array}{l}3 \mathrm{~A} \\
4 \mathrm{~A}\end{array}$ & $\begin{array}{l}6 \\
6\end{array}$ & $\begin{array}{l}524 \cdot 7 \pm 91 \cdot 0 \\
252.5 \pm 65.9\end{array}$ & $\begin{array}{l}3 B \\
4 B\end{array}$ & $\begin{array}{l}4 \\
6\end{array}$ & $\begin{array}{l}589 \cdot 0 \pm 78 \cdot 6 \\
493 \cdot 4 \pm 42 \cdot 3\end{array}$ \\
\hline
\end{tabular}

* Six ewes had one corpus luteum in the ovary adjacent and opposite to the operated uterine horn.

treatment effect on the developing CL depended upon the location of the CL relative to the operated uterine horn (group $\times$ ovary interaction, $P<0.01$ ). The GL in the ovary adjacent to the operated uterine horn were smaller in size than those in the opposite ovary (Groups A versus Groups B; $P<0.01$ ). The presence 
of the spiral in the anterior or posterior portion of the uterine horn interfered with the development of the CL in the adjacent ovary.

The $C_{L}$ in the ovary adjacent to the uterine horn of ewes with a spiral in the posterior location (Group 4A) tended to be heavier than comparable CL of ewes with a spiral in the anterior portion of the uterine horn (Group 2A). The difference was not significant statistically. The presence of a spiral in the posterior portion of the uterine horn had no apparent inhibitory effect on the $\mathrm{CL}$ in the adjacent ovary of two ewes in Group 4A. (Average wt of $\mathrm{CL}, 422.3 \mathrm{mg}$ ).

The $\mathrm{CL}$ in the ovary adjacent to the uterine horn with a spiral either in the anterior or posterior location (Groups $2 \mathrm{~A}$ and $4 \mathrm{~A}$ ) were smaller in size than CL in the ovary adjacent to the operated uterine horn of control ewes (Group 1A), but the CL in the opposite ovary of the former ewes (Groups 2B and 4B) were heavier than comparable corpora in control ewes (Group 1B; interaction, $P<0.01)$.

Oestrus was detected before Day 8 of the 'treatment' oestrous cycle in two ewes in Groups 4A and one ewe in Group 4B, but only one of the former ewes had ovulated. Each of these three ewes had a 'treatment' oestrous cycle length of 7 days. Ovulation without oestrus occurred in one ewe in both of Groups 2A and $2 \mathrm{~B}$. New CL were present at the time of autopsy on Day 8 of the oestrous cycle.

Exogenous HCG counteracted the inhibitory effect of a spiral on the GL in the adjacent ovary (Groups $3 \mathrm{~A}$ and $3 \mathrm{~B}$ versus Groups $2 \mathrm{~A}$ and $2 \mathrm{~B}, P<0.01$ ). The difference in average weight of CL in the adjacent ovary (Group 3A, anterior horn + injected HCG versus Group 2A, anterior horn) was greater than that of CL in the opposite ovary (Group 3B, anterior horn + injected HCG versus Group $2 \mathrm{~B}$, anterior horn; interaction, $P<0 \cdot 05)$.

New CL forming as a result of treatment with HCG were present in six of nine ewes in Groups 3A and 3B. The average number of new CL present in these six ewes was 3.0 (range 1 to 5 ).

Intra-uterine movement of plastic spirals, regardless of location, was negligible during the course of the experiment.

\section{Length of 'operative' oestrous cycle}

The average length of the 'operative' oestrous cycle for twenty-nine ewes with one or two cL in one ovary only are given in Table 2. There was no significant effect of intra-uterine spirals on the length of the 'operative' oestrous cycle regardless of whether the CL were in the ovary adjacent or opposite to the operated horn. Four of thirteen ewes, however, with CL only in the ovary adjacent to the uterine horn with a spiral in the anterior or posterior location had 'operative' oestrous cycles shorter than 11 days in length.

These data may differ somewhat from those of Ginther, Pope \& Casida (1966) who found that the 'operative' oestrous cycle was significantly shorter for ewes which had CL on only the operative side than for ewes which had CL only on the nonoperative side. Spirals were inserted on Day 4 of the oestrous cycle in both studies.

Eleven ewes (one control, ten treated) had one CL in each ovary at the time of initial laparotomy. The control ewe had an 'operative' oestrous cycle of 15 
days. The average length of the 'operative' oestrous cycle of seven ewes with a spiral in the anterior portion of the uterine horn was 14 days (range 7 to 18 days) and in three ewes with a spiral in the posterior uterine horn 13.7 days (range 10 to 16 days). Three ewes with one CL in each ovary and with a spiral either in the anterior or posterior portion of the uterine horn had 'operative' oestrous cycles shorter than 11 days in length.

\section{TABLE 2}

EFFEGT OF INTRA-UTERINE PLASTIC SPIRALS ON THE LENGTH OF THE 'OPERATIVE' OESTROUS CYGLE OF EWES WITH ONE OR TWO CL IN ONE OVARY ONLY

\begin{tabular}{|c|c|c|c|c|c|c|c|c|}
\hline \multirow{4}{*}{$\begin{array}{l}\text { Intra-uterine } \\
\text { location of } \\
\text { spiral }\end{array}$} & \multicolumn{8}{|c|}{ Location of corpora lutea relative to operated uterine horn } \\
\hline & \multicolumn{4}{|c|}{ Adjacent ovary } & \multicolumn{4}{|c|}{ Opposite ovary } \\
\hline & \multirow{2}{*}{$\begin{array}{l}\text { No. } \\
\text { of } \\
\text { ewes }\end{array}$} & \multirow{2}{*}{$\begin{array}{l}\text { Average } \\
\text { no. of } \\
C L / \text { ewe }\end{array}$} & \multicolumn{2}{|c|}{$\begin{array}{l}\text { Length of oestrous } \\
\text { cycle (days) }\end{array}$} & \multirow{2}{*}{$\begin{array}{l}\text { No. } \\
\text { of } \\
\text { ewes }\end{array}$} & \multirow{2}{*}{$\begin{array}{l}\text { Average } \\
\text { no. of } \\
C L / \text { ewe }\end{array}$} & \multicolumn{2}{|c|}{$\begin{array}{l}\text { Length of oestrouts } \\
\text { cycle (days) }\end{array}$} \\
\hline & & & Average & Range & & & Average & Range \\
\hline $\begin{array}{l}\text { None } \\
\text { Anterior horn } \\
\text { Posterior horn }\end{array}$ & $\begin{array}{l}5 \\
8 \\
5\end{array}$ & $\begin{array}{l}1.20 \\
1 \cdot 12 \\
1 \cdot 00\end{array}$ & $\begin{array}{l}16 \cdot 80 \\
13 \cdot 88 \\
16 \cdot 00\end{array}$ & $\begin{array}{r}16-19 \\
6-23 \\
10-23\end{array}$ & $\begin{array}{l}2 \\
5 \\
4\end{array}$ & $\begin{array}{l}1 \cdot 50 \\
1.20 \\
1 \cdot 00\end{array}$ & $\begin{array}{l}16 \cdot 50 \\
16 \cdot 20 \\
19 \cdot 25\end{array}$ & $\begin{array}{l}16-17 \\
14-18 \\
13-31\end{array}$ \\
\hline
\end{tabular}

Experiment II. Effect of intra-uterine spirals on luteal development in salpingectomized ewes

Removal of the oviducts did not prevent the inhibitory action of intra-uterine spirals on the corpus luteum. The GL of three salpingectomized control ewes at Day 8 of the oestrous cycle were heavier (average wt $588.9 \mathrm{mg}$ ) than comparable CL of four salpingectomized ewes with a spiral in the anterior portion of each uterine horn (average wt $49.6 \mathrm{mg}, P<0.05$ ).

Spirals surgically inserted into both uterine horns on Day 6 had no effect on the length of the 'operative' oestrous cycle in three ewes but one ewe returned to oestrus 2 days after surgery. The length of the subsequent oestrous cycle in three of four ewes with spirals in both uterine horns was 5 to 7 days. Ovulation without oestrus occurred in the remaining ewe.

\section{DISCUSSION}

The ability of intra-uterine devices to interfere with corpus luteum development in the cow, ewe and guinea-pig appears to involve a local utero-ovarian mechanism.

The presence of a spiral in the anterior portion of the uterine horn of the ewe results in a local inhibition of the CL in the adjacent ovary (Ginther, Pope \& Casida, 1966). The present experiments demonstrate that a spiral in the posterior portion of the uterine horn also inhibits development of CL in the adjacent ovary.

The administration of gonadotrophin (HCG) from Day 3 to 6 of the oestrous cycle counteracted the inhibitory effect of an intra-uterine spiral on the corpus luteum. It is possible that this stage of the cycle (Day 3 to 6 ) corresponds to the period during which the CL is susceptible to the adverse effect of the presence 
of a spiral in the uterine horn or that the uterine horn, stimulated by the presence of the spiral, exerts its inhibitory effect only during this time. If the CL remains susceptible to a possible inhibitory effect of an intra-uterine spiral beyond Day 5 of the oestrous cycle, the exogenous gonadotrophin may render the cL refractory to any inhibitory action of the spiral after this stage of the cycle.

The mechanism(s) by which intra-uterine devices inhibit luteal development is unknown. The presence of a spiral may stimulate the uterus to produce a substance which reaches the ovary through a local pathway and interferes with development of the corpus luteum. These studies fail to implicate the oviduct as a major pathway through which the local inhibitory effect of the spiral on the GL is mediated.

\section{ACKNOWLEDGMENTS}

This study was supported in part by a reimbursable agreement with the National Institute of Child Health and Human Development, National Institutes of Health, Bethesda, Maryland, U.S.A.

\section{REFERENCES}

Bland, K. P. \& Donovan, B. T. (1965a) A quantitative study of the effect of uterine distension on the oestrous cycle of the guinea-pig. F. Physiol., Lond. 179, 34.

Bl.AND, K. P. \& Donovan, B. T. (1965b) Local control of luteal function by the uterus of the guinea-pig. Nature, Lond. 207, 867.

Ginther, O. J., Pope, A. L. \& Casida, L. E. (1966) Local effect of an intra-uterine plastic coil on the corpus luteum of the ewe. F. Anim. Sci. 25, 472.

Ginther, O. J., Woody, C. O., Janakiraman, K. \& Casida, L. E. (1966) Effect of an intra-uterine plastic coil on the oestrous cycle of the heifer. F. Reprod. Fert. 12, 193.

Hansel, W. \& WAgneR, W. C. (1960) Luteal inhibition in the bovine as a result of oxytocin injections, uterine dilatation, and intrauterine infusions of seminal and preputial fluids. F. Dairy Sci. 43, 796.

Hawk, H. W., Conley, H. H., Brinsfield, T. H. \& Righter, H. F. (1964) Contraceptive effect of plastic devices in cattle uteri. Proc. 2nd int. Conf. Intra-uterine Contraception. Eds. S. J. Segal, A. L. Southam and K. D. Shafer. Excerpta Medica Foundation, New York.

Inskeep, E. K., Oloufa, M. M., Howland, B. E., Pope, A. L. \& Gasida, L. E. (1962) Effect of experimental uterine distension on estrual cycle lengths in ewes. $\mathcal{7}$. Anim. Sci. 21, 331.

Moore, W. W. \& Nalbandov, A. V. (1953) Neurogenic effects of uterine distension on the estrous cycle of the ewe. Endocrinology, 53,1. 